\title{
Physiological Responses of Hard Red Winter Wheat to Infection by Wheat streak mosaic virus
}

\author{
Gautam P. Pradhan, Qingwu Xue, Kirk E. Jessup, Baozhen Hao, Jacob A. Price, and Charles M. Rush
}

First author: Williston Research Extension Center, North Dakota State University, Williston 58801; and second, third, fourth, fifth, and sixth authors: Texas A\&M AgriLife Research and Extension Center at Amarillo, Amarillo, TX 79106.

Accepted for publication 18 December 2014.

\begin{abstract}
Pradhan, G. P., Xue, Q., Jessup, K. E., Hao, B., Price, J. A., and Rush, C. M. 2015. Physiological responses of hard red winter wheat to infection by Wheat streak mosaic virus. Phytopathology 105:621-627.

Wheat streak mosaic virus (WSMV) causes significant yield loss in hard red winter wheat in the U.S. Southern High Plains. Despite the prevalence of this pathogen, little is known about the physiological response of wheat to WSMV infection. A 2-year study was initiated to (i) investigate the effect of WSMV, inoculated at different development stages, on shoot and root growth, water use, water use efficiency (WUE), and photosynthesis and (ii) understand the relationships between yield and photosynthetic parameters during WSMV infection. Two greenhouse experiments were conducted with two wheat cultivars mechanically inoculated with WSMV at different developmental stages, from three-leaf to booting. WSMV inoculated early, at three- to five-leaf stage, resulted in

a significant reduction in shoot biomass, root dry weight, and yield compared with wheat infected at the jointing and booting stages. However, even when inoculated as late as jointing, WSMV still reduced grain yield by at least $53 \%$. Reduced tillers, shoot biomass, root dry weight, water use, and WUE contributed to yield loss under WSMV infection. However, infection by WSMV did not affect rooting depth and the number of seminal roots but reduced the number of nodal roots. Leaf photosynthetic parameters (chlorophyll [SPAD], net photosynthetic rate [Pn], stomatal conductance [Gs], intercellular $\mathrm{CO}_{2}$ concentration [Ci], and transpiration rate [Tr]) were reduced when infected by WSMV, and early infection reduced parameters more than late infection. Photosynthetic parameters had a linear relationship with grain yield and shoot biomass. The reduced Pn under WSMV infection was mainly in response to decreased $\mathrm{Gs}, \mathrm{Ci}$, and SPAD. The results of this study indicated that leaf chlorophyll and gas exchange parameters can be used to quantify WSMV effects on biomass and grain yield in wheat.
\end{abstract}

Wheat (Triticum aestivum L.) is one of the most important field crops grown in the Great Plains of the United States. The percentage of winter wheat production in the region ranged from 45 to $58 \%$ of the national total, with an average of 21.4 million tons from 2011 to 2013 (National Agricultural Statistics Services, 2013). In the southern Great Plains, winter wheat is often grown as dual purpose for both winter grazing and grain production. Studies have shown that wheat intended for grazing, which is planted in late summer or early fall, is more prone to biotic stress, compared with wheat planted for grain only, which is planted in middle to late fall (Hansing et al. 1950; Hunger et al. 1992, 2010).

Wheat streak mosaic virus (WSMV), which belongs to the family Potyviridae (Stenger et al. 1998) and is vectored by the wheat curl mite (Aceria tosichella Keifer) (Slykhuis 1955), has been identified as the most prevalent virus disease throughout the western Great Plains (Burrows et al. 2009; Byamukama et al. 2013; Workneh et al. 2008). Symptoms of wheat streak mosaic (WSM), caused by WSMV, include leaf chlorosis, mosaic, streaking, and stunting (Hadi et al. 2011; Hansing et al. 1950; Hunger et al. 2010; Navia et al. 2013). Under optimum environmental conditions for vector reproduction and disease development, WSM can result in total yield loss in individual fields (Byamukama et al. 2013; Hadi et al. 2011; Price et al. 2010). These losses result from a reduction in root biomass, leaf chlorophyll, above-ground biomass, yield components, and water use efficiency (WUE) (Byamukama et al. 2014; Langham et al. 1996; Price et al. 2010; Workneh et al. 2010).

The degree of yield loss by WSMV infection is related to several factors, including time of infection, age of plants, cultivar, and soil

Corresponding author: Q. Xue; E-mail address: qxue@ag.tamu.edu water availability. In recent studies, Price et al. (2010) and Byamukama et al. (2014) showed that there was genotypic variation in susceptibility to WSMV. There was no significant effect of WSMV on yield in resistant genotypes KS 10-3 or Mace, but WSMV decreased grain yield by 50 to $62 \%$ in susceptible genotypes Karl and Millennium. Hunger et al. (1992) conducted 2-year field studies and showed that there was up to $87 \%$ yield reduction in seven wheat cultivars planted in the early fall (12 September) and inoculated with WSMV on 4 November; but the spring inoculation (24 March) did not cause significant yield reduction in early fall planted wheat. However, the spring inoculation reduced yield by $>75 \%$ in wheat planted in late fall on 9 November. These findings demonstrated that plant development stage at the time of inoculation with WSMV could affect disease severity, with older plants being more resistant than younger plants. This supported an earlier report by Hansing et al. (1950) that younger wheat was more susceptible to infection. However, in these studies, the mechanisms by which WSMV impacted wheat at different developmental stages were not determined.

In the Texas High Plains, high grain yields rely on irrigation because of the scarcity of precipitation and associated drought stress. The irrigation water is mainly from the Ogallala Aquifer, which is essentially a closed system with minimal recharge capacity. Over the last 50 years, water tables in the aquifer have reduced up to $50 \%$, mostly due to the water extraction for irrigation. With declining water supplies from the aquifer and increasing energy costs, irrigation management is increasingly important for sustainable wheat production, and adding irrigation to a diseased wheat crop with low yield potential is not environmentally or economically sustainable. Managing fields of irrigated wheat infected with WSM presents a particularly difficult challenge for producers. Price et al. (2010) showed that WSMV infection not only affected forage and grain yields but also significantly reduced plant WUE, due to a reduction of both shoot biomass and root dry weight. Furthermore, because the 
wheat curl mite is spread across fields by wind, disease severity gradients develop over time, leaving farmers to question whether continued crop inputs, such as supplemental fertilization, pest control, and irrigation are economically feasible. For this reason, it is important to further investigate the effects of WSMV infection on wheat at different developmental stages (Workneh et al. 2010).

A study was initiated with the following objectives: (i) investigate the effect of WSMV infection of wheat, at different developmental stages, on growth traits, yield, and photosynthetic parameters, and (ii) understand the relationships between yield and photosynthetic parameters of wheat infected by WSMV.

\section{MATERIALS AND METHODS}

Plant material, growing conditions, and treatments. Greenhouse experiments were conducted at Texas A\&M AgriLife Research Station, Bushland, Texas in 2011 and 2012, using two hard red winter wheat cultivars; TAM 105, which is susceptible to WSMV, and TAM 112, which has tolerance to WSMV and resistance against the wheat curl mite (Price et al. 2014). For both experiments, wheat seeds were germinated in ice trays and vernalized at $4{ }^{\circ} \mathrm{C}$ for 6 weeks in experiment I (2011) and 7 weeks in experiment II (2012). The vernalized seedlings (about two-leaf stage) were then transplanted to PVC pots $(7.6 \mathrm{~cm}$ inter diameter and $84 \mathrm{~cm}$ tall) with one plant per pot. In experiment I, pots were filled with a mixture of Pullman clay loam soil and sand at 50:50 ratio (Price et al. 2010). In experiment II, pots were filled with Turface (Turface, Buffalo Grove, IL), a synthetic soil mixture used to facilitate extraction of roots.

Plants were grown in the greenhouse from transplanting to maturity, under well-watered conditions. In experiment I, there were five treatments, which consisted of plants mechanically inoculated with WSMV (Price et al. 2010) at three-leaf, five-leaf, jointing, and booting stages, and a noninoculated control. Experiment II was designed to repeat the treatments in experiment I, but only three treatments, WSMV inoculated at four-leaf, jointing, and the noninoculated control, were achieved because the wheat plants developed faster than those in experiment I. As a result, the earliest inoculation was made at the four-leaf stage and although plants were inoculated with WSMV at booting, for unknown reasons no infection developed. The faster development in plants in experiment II could be related to longer vernalization than those in experiment I, since the average temperature was slightly lower in experiment II than experiment I (see results).

Treatments were applied randomly to different pots of each cultivar at different developmental stages, and pots receiving mock inoculation with buffer only served as the WSMV negative controls. Virus inoculum was prepared as previously described (Price et al. 2014) with WSMV-infected wheat leaves collected the previous year and preserved at $-20^{\circ} \mathrm{C}$. Forty grams of infected tissue was macerated in a blender with 1 liter of freshly prepared $0.1 \mathrm{M}$ potassium phosphate buffer. The inoculum $(500 \mathrm{ml})$ plus $1 \mathrm{~g}$ of 600 -grit Carborundum (silicon carbide powder) was sprayed on wheat leaves at $0.41 \mathrm{MPa}$ pressure, with a spray paint gun connected to an air compressor. Twelve days after inoculation, infection was verified by doubleantibody sandwich enzyme-linked immunosorbent assay, using standard Agdia protocol (Elkhart, IN). For each treatment, eight pots of infected plants were randomly selected, and each of four pots were used for data collections at anthesis and maturity, respectively.

Measurements of photosynthetic parameters, water use, and water use efficiency (WUE). Leaf photosynthetic parameters were measured at anthesis from the middle portion of fully expanded flag leaves. Leaf chlorophyll content was measured with a self-calibrating chlorophyll meter (Soil Plant Analytical Device (SPAD), Model 502, Spectrum Technologies, Plainfield, IL) and presented as SPAD units. The gas exchange parameters, i.e., net photosynthetic rate $\left(\mathrm{Pn}, \mu \mathrm{mol} \mathrm{m}{ }^{-2} \mathrm{~s}^{-1}\right)$, stomatal conductance (Gs, mol m $\left.\mathrm{m}^{-2} \mathrm{~s}^{-1}\right)$, intercellular $\mathrm{CO}_{2}$ concentration $\left(\mathrm{Ci}, \mu \mathrm{mol} \mathrm{mol} \mathrm{m}^{-1}\right)$, and transpiration rate $\left(\mathrm{Tr}, \mathrm{mmol} \mathrm{m} \mathrm{m}^{-2} \mathrm{~s}^{-1}\right)$, were measured with a Li-Cor 6400 portable photosynthesis system (Li-Cor, Inc., Lincoln, NE). The internal LED light source was set at 1,600 $\mu \mathrm{mol}$ $\mathrm{m}^{-2} \mathrm{~s}^{-1}$ to ensure a constant uniform light across all measurements.

During the growing period from transplanting to maturity, soil water level was kept at $100 \%$ of pot capacity based on the procedure of Xue et al. (2012). Plants were irrigated every 3 days by adding the amount of water needed to bring pots back to $100 \%$ pot capacity. Before transplanting, the weights of empty pots and pots with airdried soil mixture were recorded. Each pot was then saturated with water for 2 days, and water was allowed to drain for $>48 \mathrm{~h}$. When drainage stopped, weight of each pot was recorded again, which was the weight at $100 \%$ pot capacity. In each treatment for each cultivar, water use was calculated by weighing three pots when they were watered. Water use was defined as the difference between the weight at $100 \%$ pot capacity and at time of watering. The total water use was determined by accumulating the water use from transplanting to maturity (Xue et al. 2012). The WUE for biomass and for grain yield was calculated as the ratio of shoot biomass and grain yield to total water use, respectively (Xue et al. 2014).

Measurements of growth traits and yield. At anthesis, plants were harvested and shoots and roots were separated above the crown. For shoot samples, the numbers of stems and spikes were counted. Then, the stems and spikes were put in separate bags. For processing root samples, soil cores were carefully removed from PVC pots. Then, the rooting depth was determined by measuring the length from crown to the lowest point that roots were visible. After roots were washed, the numbers of seminal and nodal roots were counted. The identification of the root types was based on Klepper et al. (1982). All the shoot and root samples were dried at $60^{\circ} \mathrm{C}$ for at least $48 \mathrm{~h}$, and dry weights were recorded. At maturity, only above-ground parts were harvested for determining stem, spike, and shoot dry weights. Grain yield was determined after threshing the mature spikes.

Data analysis. The experiment was a completely randomized design with four replications in experiment I and six replications in experiment II. The data were analyzed using PROCEDURE GLIMMIX (SAS 9.13), and treatment means were compared using LSMEANS with the PDIFF option at $P=0.05$ level. Data were analyzed considering replication as a random factor and all others as fixed factors.

\section{RESULTS}

In experiment $\mathrm{I}$, average maximum and minimum temperatures from transplanting to maturity in greenhouse were 30.1 and $16.5^{\circ} \mathrm{C}$, and the relative humidity was 32 and $69 \%$, respectively. In experiment II, the average maximum temperature was lower $\left(26.0^{\circ} \mathrm{C}\right)$. However, the average minimum temperature $\left(17.0^{\circ} \mathrm{C}\right)$ and relative humidity ( 32 to $69 \%$ ) were the same as experiment I.

There was a significant effect of WSMV treatment (inoculated at different developmental stages; T) on most of the physiological parameters, growth, and yield traits $(P<0.05)$; however, the effects of cultivar $(\mathrm{C})$ and the interaction effect of $\mathrm{C} \times \mathrm{T}$ were not significant for most of the traits $(P>0.05)$ (Table 1$)$. Therefore, the averages of cultivars are presented and discussed below. In general, infection by WSMV considerably reduced growth, yield, and photosynthetic efficiency.

Growth, yield, water use, and WUE. There was a 62 to $71 \%$ decrease in stems per plant in wheat inoculated at three- to fiveleaf stages compared with the control in both experiments. In wheat inoculated at jointing and the booting stages, the decrease in the number of stems was 41 to $45 \%$. There was 48 to $57 \%$ decrease in spikes per plant in wheat inoculated at three-leaf and five-leaf stage compared with the control in experiment I. In experiment II, there was a $93 \%$ decrease in spikes from plants inoculated at the four-leaf stage. In wheat inoculated at jointing, spikes per plant were not reduced compared with the noninoculated control. There was no difference in most of the growth traits at anthesis, between 
all reduced compared with control plants. However, WSMV did not affect $\mathrm{Ci}$ (Fig. 2F to J). Figure 3 shows that $\mathrm{Pn}$ was positively related to $\mathrm{Gs}$, Tr, and $\mathrm{Ci}$. Although the relationships between $\mathrm{Gs}$, Tr, and $\mathrm{Pn}$ were curvilinear, Pn decreased as Gs, Tr, and Ci decreased. Therefore, the reduction of Pn under WSMV infection was mainly caused by stomatal closure. The photosynthetic capacity of the chloroplast may not be reduced.

The relationships between photosynthetic parameters and grain yield and shoot biomass in experiment I are presented in Figure 4. There were strong linear relationships of SPAD, Pn, Gs, and Tr with grain yield and shoot biomass, with $R^{2}$ ranging from 0.78 to 0.99 $(P<0.05)$. The linear relationship between $\mathrm{Ci}$ and grain yield was only significant at $P=0.09$ but the relationship between $\mathrm{Ci}$ and shoot biomass was still significant at $P<0.01$. It is clear that the earlier the virus infection, the higher the decrease in photosynthetic parameters, and subsequently grain yield and shoot biomass. There was a linear relationship between grain yield and shoot biomass $\left(R^{2}=0.82\right)$. This further showed that the decrease in photosynthetic parameters due to infection at an early stage of wheat development decreased above-ground biomass, which ultimately caused a decline in grain yield.

\section{DISCUSSION}

In this study, two experiments were conducted to investigate the effect of WSMV infection at different developmental stages on wheat growth, yield and photosynthesis parameters. In experiment I, there were five treatments with WSMV inoculated at three-leaf, five-leaf, jointing, and booting stages, and a noninoculated control. Although the experiment II was designed to repeat the treatments in experiment I, but only three treatments (WSMV inoculated at four-leaf, jointing, and control) were achieved because the wheat plants developed faster than those in experiment I. Wheat development is affected by temperature, vernalization, and photoperiod (Robertson et al. 1996). Since the photoperiod in two experiments were similar and average temperature of experiment II was lower than that of experiment I, the faster development in plants in experiment II could be related to longer vernalization than those in experiment I. In general, wheat plants with longer vernalization have less main stem leaves and greater leaf appearance rate, which result in faster development (Cutforth et al. 1992; Wang et al. 1995). Despite the differences in plant developmental stages at inoculation, the general results of the two experiments were the same.

The results from both experiments showed that WSMV infection can significantly reduce plant growth, yield, water use, and WUE (either based on biomass or grain yield), which is consistent with results from previous studies (Hunger et al. 1992; Price et al. 2010). However, this study was unique because it identified and quantified factors that impacted these plant variables. The reduction of growth parameters and yield by WSMV was largely related to the developmental stage when plants were infected by WSMV, and early infection (e.g., three- to five-leaf stage) always resulted in greater reductions in growth and yield than later infection. Hunger, et al. (1992) investigated the effects of WSMV on tillering, yield, and 1,000-kernel weight (TKW) in wheat inoculated either in the fall or spring. In general, the fall WSMV inoculation considerably reduced wheat yield and TKW. However, the spring inoculation with WSMV did not consistently reduce yield or TKW. The main difference between fall and spring inoculations was plant developmental stage. Plants inoculated in the fall were generally at the three- to five-leaf stage while those in the spring treatment were inoculated at jointing. Hunger et al. (1992) concluded that since

TABLE 3. Growth traits, total water use, and water use efficiency (WUE) for biomass (WUEbm) and for grain yield (WUEg) at maturity as influenced by Wheat streak mosaic virus inoculated at different developmental stages

\begin{tabular}{|c|c|c|c|c|c|c|}
\hline Treatments & $\begin{array}{l}\text { Stem dry weight } \\
\left(\mathrm{g} \text { plant }^{-1}\right)\end{array}$ & $\begin{array}{l}\text { Spike dry weight } \\
\left(\mathrm{g}_{\text {plant }}^{-1}\right)\end{array}$ & $\begin{array}{l}\text { Shoot biomass } \\
\left(\text { g plant }^{-1}\right)\end{array}$ & $\begin{array}{l}\text { Total water use } \\
\left(\mathrm{kg} \mathrm{plant}^{-1}\right)\end{array}$ & WUEbm $\left(\mathrm{g} \mathrm{kg}^{-1}\right)$ & WUEg $\left(\mathrm{g} \mathrm{kg}^{-1}\right)$ \\
\hline \multicolumn{7}{|l|}{ Experiment I } \\
\hline Three-leaf & $0.45 \mathrm{c}^{\mathrm{y}}$ & $1.00 \mathrm{c}$ & $1.45 \mathrm{c}$ & $4.19 \mathrm{c}$ & $0.22 \mathrm{~b}$ & $0.09 \mathrm{~b}$ \\
\hline Jointing & $1.04 \mathrm{bc}$ & $1.50 \mathrm{c}$ & $2.54 \mathrm{c}$ & $7.84 \mathrm{ab}$ & $0.37 \mathrm{~b}$ & $0.15 \mathrm{~b}$ \\
\hline Booting & $1.67 \mathrm{a}$ & $3.64 \mathrm{~b}$ & $5.30 \mathrm{~b}$ & $7.32 \mathrm{ab}$ & $0.70 \mathrm{a}$ & $0.33 \mathrm{a}$ \\
\hline Control & $1.92 \mathrm{a}$ & $5.80 \mathrm{a}$ & $7.72 \mathrm{a}$ & $9.15 \mathrm{a}$ & $0.85 \mathrm{a}$ & $0.44 \mathrm{a}$ \\
\hline \multicolumn{7}{|l|}{ Experiment II } \\
\hline Control & $2.69 \mathrm{a}$ & $3.48 \mathrm{a}$ & $6.17 \mathrm{a}$ & - & - & - \\
\hline
\end{tabular}

y Different letters within a column denote significant difference at $P=0.05$.

z Data not collected.

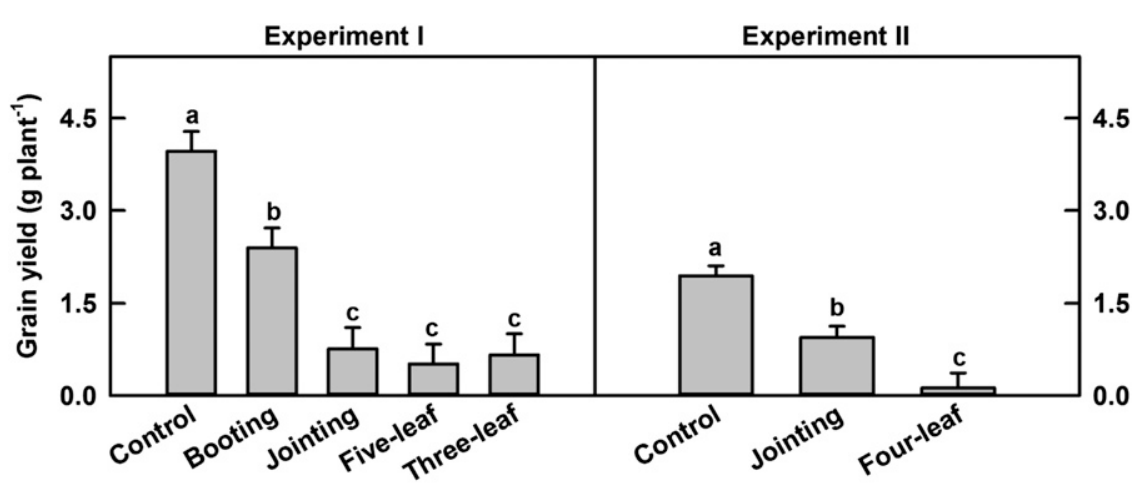

Treatments (wheat stage at the time of virus inoculation)

Fig. 1. Grain yield as influenced by the Wheat streak mosaic virus inoculated at different developmental stages. The vertical line above the bar denotes standard error of the mean; and bars with same letter on top are statistically not significant at $P=0.05$. 
wheat plants are generally more resistant to WSMV at later developmental stages than those at early developmental stages, yield loss could be small with late inoculations. However, significant WSMV disease symptoms were still observed when plants were inoculated at jointing stage in this study. Compared with field conditions, mechanical inoculation of WSMV in greenhouse may result in higher disease pressure because the environment is more conducible for disease development. Nevertheless, disease infection at later developmental stages has less time to disrupt plant physiological parameters and growth, which result in less yield reduction. In experiment I of this study, inoculation of plants as late as booting reduced grain yield, and in both experiments inoculations at the three- to five-leaf stage through jointing resulted in significant reductions in both shoot biomass and grain yield (up to $90 \%$ ) when compared with the noninoculated control. These results are important for irrigation management of WSMV-infected wheat.

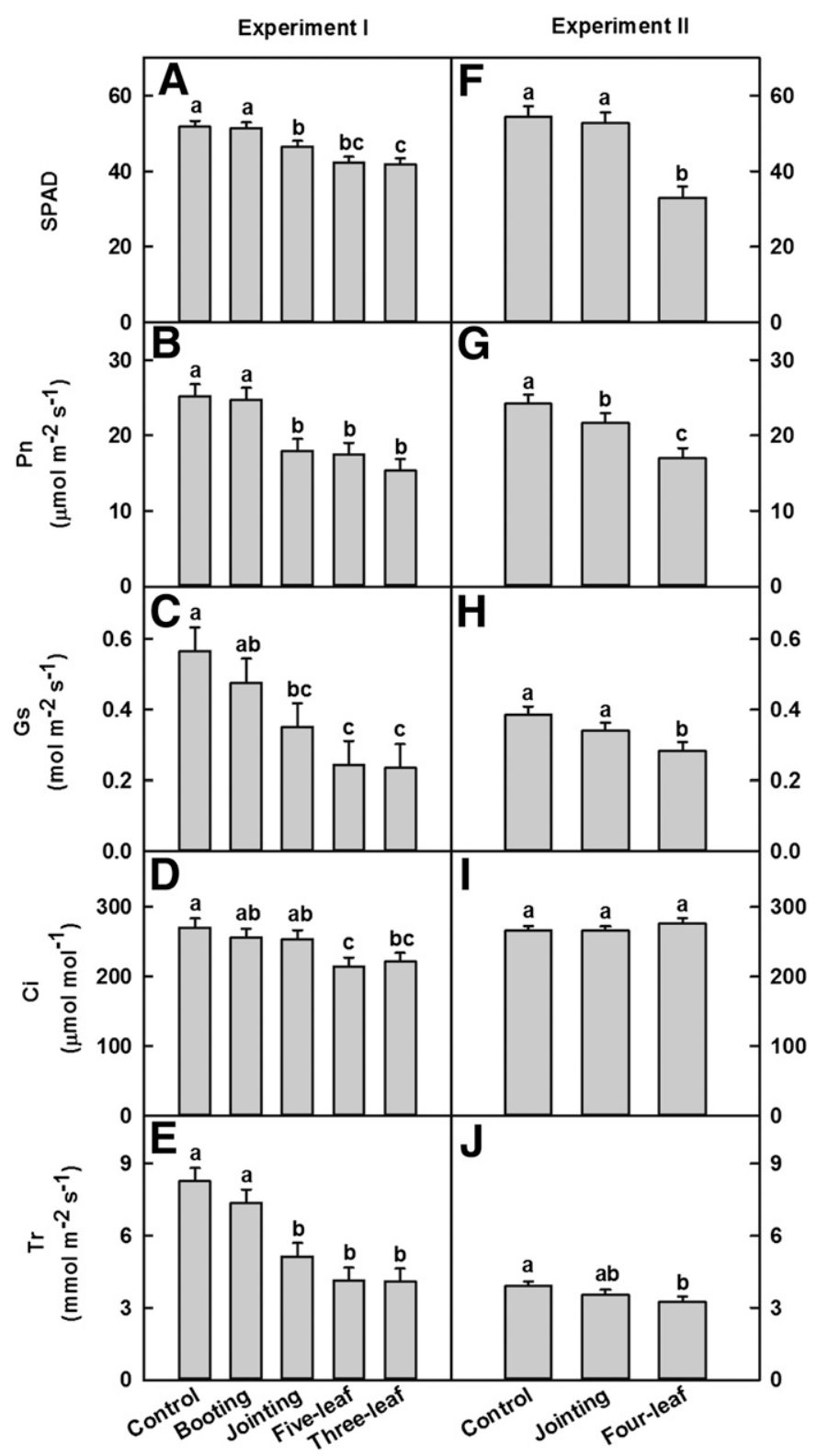

Treatments (wheat stage at the time of virus inoculation)

Fig. 2. Physiological parameter as influenced by Wheat streak mosaic virus inoculated at different developmental stages. The vertical line above the bar denotes standard error of the mean; and bars with same letter on top are statistically not significant at $P=0.05$. SPAD $=$ chlorophyll reading; $\mathrm{Pn}=$ net photosynthetic rate; $\mathrm{Gs}=$ stomatal conductance; $\mathrm{Ci}=$ intercellular $\mathrm{CO}_{2}$ concentration; and $\operatorname{Tr}=$ transpiration rate.
If plants become infected at jointing or earlier, it would not be economically or environmentally advisable to continue full irrigation because the reduced grain yields associated with early infection would not cover the expense of the irrigation and the infected plants would not be able to efficiently use the applied water.

Grain yield reduction in plants infected with WSMV was a result of reduced tillers and shoot and root dry weights. Similarly, previous studies also showed that reduced tiller production and shoot and root dry weights were major causes of yield loss under WSMV infection (Byamukama et al. 2014; Hunger et al. 1992; Price et al. 2010). The WSMV infection significantly reduced root dry weight and WUE (either based on biomass or grain yield) in this study.
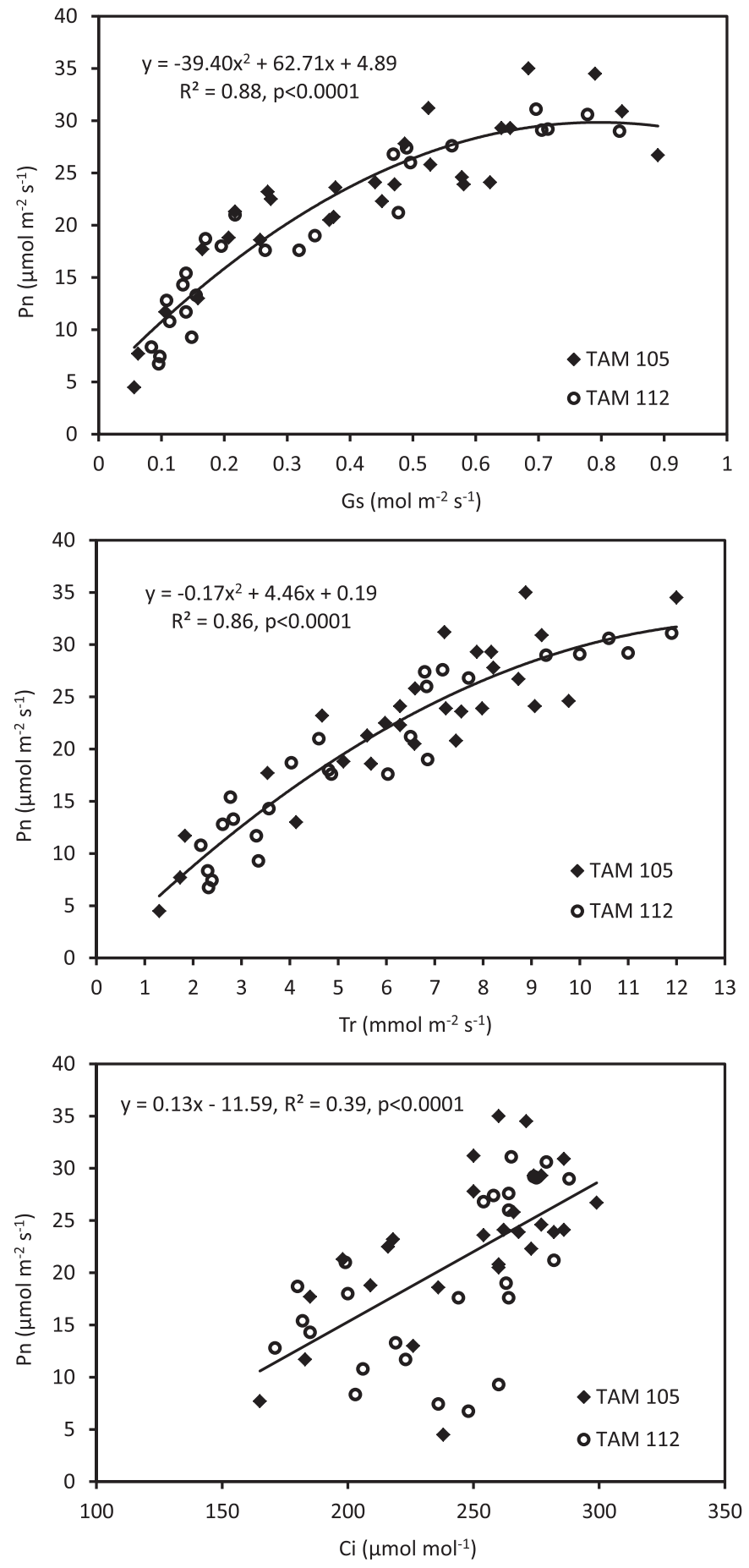

Fig. 3. Relationships between net photosynthetic rate $(\mathrm{Pn})$ and stomatal conductance (Gs), transpiration rate (Tr), and intercellular $\mathrm{CO}_{2}$ concentration $(\mathrm{Ci})$ in experiment $\mathrm{I}$. 
These results are consistent with a previous study at same location (Price et al. 2010). In addition to root dry weight, the impact of WSMV infection on rooting depth, and the number of seminal and nodal roots were also determined in this study. The WSMV infection did not affect rooting depth and the number of seminal roots but significantly reduced the number of nodal roots. The reduced root dry weight and number of nodal roots associated with infection by WSMV resulted in less water use and uptake and lower WUE. However, it should be noted that this study was conducted under well-watered conditions, and under field condition in the Texas High Plains, soil water stress usually occurs even under irrigation. As such, further studies conducted at various soil water regimes are needed to elucidate the interaction of water stress and WSMV infection at different developmental stages.

The reduced yield and biomass accumulation in plants affected by diseases often are caused by either decreasing light interception due to lower leaf area or photosynthetic efficiency or both (Moriondo et al. 2005). In this study in plants infected by WSMV, both reduced light interception and photosynthetic efficiency contributed to reduced shoot biomass and grain yield. Light interception is related to several factors such as plant height, leaf area, and the number of tillers. Although we did not directly measure leaf area, the stunted plants and
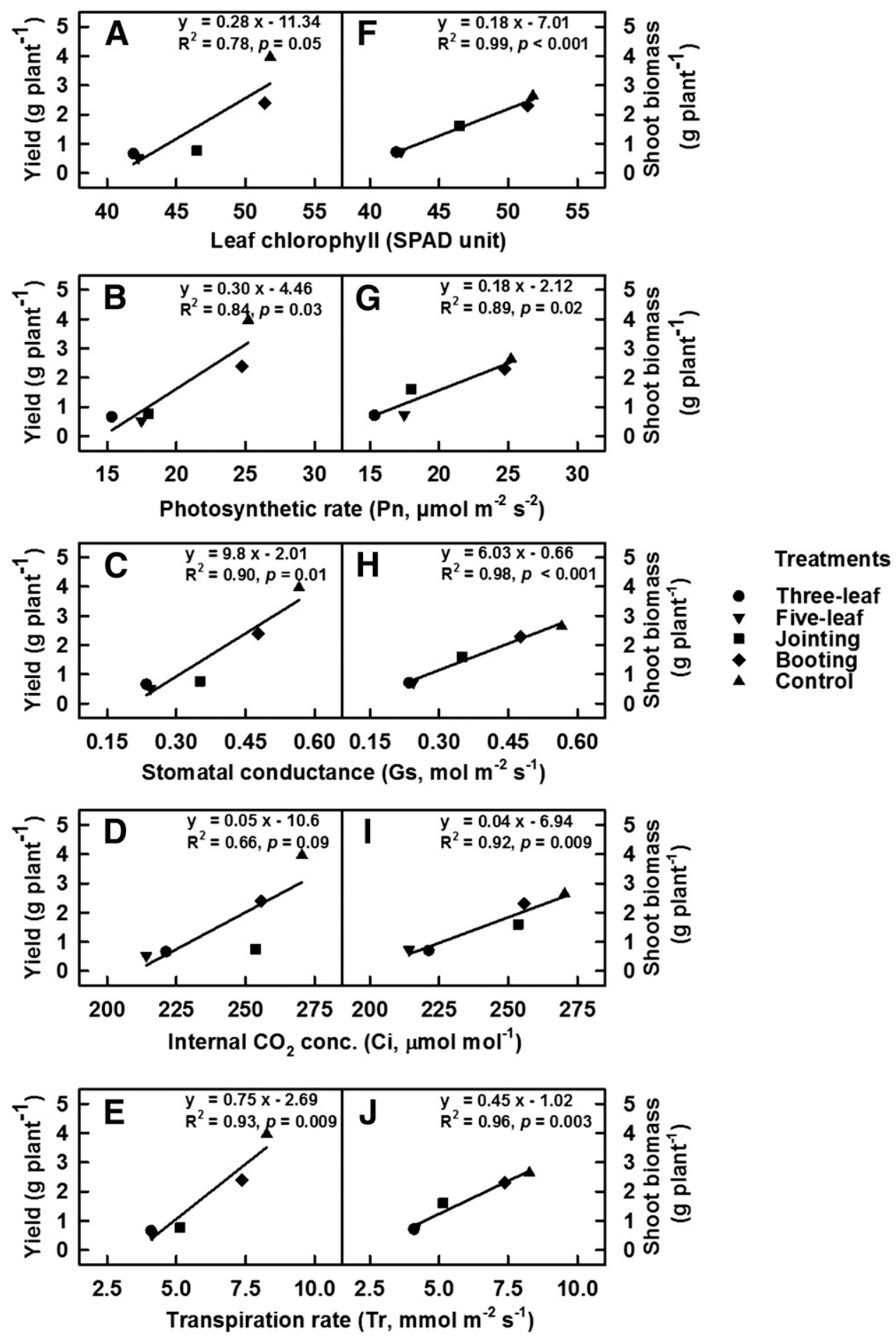

Fig. 4. Relationship of physiological traits with $\mathbf{A}$ to $\mathbf{E}$, grain yield and $\mathbf{F}$ to $\mathbf{J}$, shoot biomass as influenced by Wheat streak mosaic virus inoculated at different developmental stages in experiment I. 
reduced number of stems associated with WSMV infection explained the low light interception. In general, early inoculations resulted in greater reductions in photosynthetic efficiency. WSMV infection significantly reduced leaf chlorophyll content as indicated by lower SPAD readings. Byamukama et al. (2014) also found that leaf SPAD units were linearly related on grain yield and shoot biomass in a WSMV susceptible cultivar (Millennium) but not related to yield and shoot biomass in a WSMV resistant cultivar (Mace), under WSMV infection.

WSMV infection significantly reduced leaf gas exchange parameters $(\mathrm{Pn}, \mathrm{Gs}, \mathrm{Tr}$, and $\mathrm{Ci})$ in this study. The reduced $\mathrm{Pn}$ under WSMV infection was mainly caused by reduced Gs, Tr, and Ci (Fig. 3). In contrast, Balota et al. (2005) showed that take-all disease infection did not affect stomatal conductance (Gs) but increased intercellular $\mathrm{CO}_{2}$ concentration $(\mathrm{Ci})$. The results of this study were similar to those found in a study of mildews on grapes (Moriondo et al. 2005). They showed that the reduced $\mathrm{Pn}$ in grapevine leaves with downy and powdery mildew was a result of reduced $\mathrm{Ci}$ and photosynthetic pigments. The sensitivity of leaf gas exchange to infection by WSMV suggested that the gas exchange parameters may be used to quantify the effects of WSM on biomass production and grain yield.

\section{ACKNOWLEDGMENTS}

We thank the Texas A\&M AgriLife Research staff members and student workers J. Arthur, J. Noggler, K. Britten, J. Hicks, and C. Reynolds for their help in experiments. This research was supported in part by the United States Department of Agriculture (USDA) Ogallala Aquifer Program, a consortium between the USDA-Agricultural Research Service, Kansas State University, Texas A\&M AgriLife Research, Texas A\&M AgriLife Extension Service, Texas Tech University, and West Texas A\&M University.

\section{LITERATURE CITED}

Balota, M., Rush, C. M., Payne, W. A., and Lazar, M. D. 2005. The effect of take-all disease on gas-exchange rates and biomass in two winter wheat lines with different drought response. Plant Soil 275:337-348.

Burrows, M., Franc, G., Rush, C., Blunt, T., Ito, D., Kinzer, K., Olson, J., O'Mara, J., Price, J., Tande, C., Ziems, A., and Stack, J. 2009. Occurrence of viruses in wheat in the Great Plains region, 2008. Plant Health Prog.

Byamukama, E., Seifers, D. L., Hein, G. L., De Wolf, E., Tisserat, N. A., Langham, M. A. C., Osborne, L. E., Timmerman, A., and Wegulo, S. N. 2013. Occurrence and distribution of Triticum mosaic virus in the central Great Plains. Plant Dis. 97:21-29.

Byamukama, E., Tatineni, S., Hein, G. L., Graybosch, R., Baenziger, P. S., French, R., and Wegulo, S. N. 2014. Quantification of the grain yield loss associated with single and double infections of winter wheat by Triticum mosaic virus and Wheat streak mosaic virus. Plant Dis. 98:127-133.

Cutforth, H. W., Jame, Y. W., and Jefferson, P. G. 1992. Effect of temperature, vernalization and water stress on phyllochron and final main-stem leaf number of HY320 and Neepawa spring wheat. Can. J. Plant Sci. 72:1141-1151.

Hadi, B. A. R., Langham, M. A. C., Osborne, L., and Tilmon, K. J. 2011. Wheat streak mosaic virus on wheat: Biology and management. J. Integ. Pest Mngmt. 2:1-5.
Hansing, E. D., Melchers, L. E., Fellows, H., and Johnston, C. O. 1950. Kansas Phytopathological Notes 1949. Kansas Academy of Science, Topeka, KS.

Hunger, R. M., Sherwood, J. L., Evans, C. K., and Montana, J. R. 1992. Effects of planting date and inoculation date on severity of wheat streak mosaic in hard red winter wheat cultivars. Plant Dis. 76:1056-1060.

Hunger, R. M., Royer, T. A., Olson, J., and Edwards, J. T. 2010. Wheat streak mosaic and high plains viruses in Oklahoma. Oklahoma Cooperative Extension Service, Still Water, OK. http://digitalprairie.ok.gov/cdm/singleitem/ collection/stgovpub/id/17278/rec/2

Klepper, B., Rickman, R. W., and Peterson, C. M. 1982. Quantitative characterization of vegetative development in small cereal grains. Agron. J. 74: 789-792.

Langham, M. A. C., Gellner, J., and Gallenberg, D. J. 1996. Effects of drought stress and wheat streak mosaic virus on yield and growth characteristics in winter wheat. Pages 111-117 in: Proceedings of the South Dakota Academy of Science. South Dakota Academy of Science, Vermillion, SD.

Moriondo, M., Orlandini, S., Giuntoli, A., and Bindi, M. 2005. The effect of downy and powdery mildew on grapevine (Vitis vinifera L.) leaf gas change. J. Phytopathol. 153:350-357.

National Agricultural Statistics Services (NASS).2013. Small Grains 2013 Summary. http://usda.mannlib.cornell.edu/usda/current/SmalGraiSu/SmalGraiSu09-30-2013.pdf

Navia, D., De Mendonca, R. S., Skoracka, A., Szydło, W., Knihinicki, D., Hein, G. L., da Silva Pereira, P. R., Truol, G., and Lau, D. 2013. Wheat curl mite, Aceria tosichella, and transmitted viruses: An expanding pest complex affecting cereal crops. Exp. Appl. Acarol. 59:95-143.

Price, J. A., Workneh, F., Evett, S. R., Jones, D. C., Arthur, J., and Rush, C. M. 2010. Effects of wheat streak mosaic virus on root development and wateruse efficiency of hard red winter wheat. Plant Dis. 94:766-770.

Price, J. A., Rashed, A., Simmons A., Workneh, F., and Rush, C. M. 2014. Winter wheat cultivars with temperature sensitive resistance to Wheat streak mosaic virus do not recover from early season infections. Plant Dis. 98: 4 525-531.

Robertson, M. J., Brooking, I. R., and Ritchie, J. T. 1996. Temperature response of vernalization in wheat: Modelling the effect on the final number of mainstem leaves. Ann. Bot. (Lond.) 78:371-381.

Slykhuis, J. T. 1955. Aceria tulipae Keifer (Acarina: Eriophyidae) in relation to the spread of wheat streak mosaic. Phytopathology 45:116-128.

Stenger, D. C., Hall, J. S., Choi, I.-R., and French, R. 1998. Phylogenetic relationships within the family Potyviridae: Wheat streak mosaic virus and Brome streak mosaic virus are not members of the genus Rymovirus. Phytopathology 88:782-787.

Wang, S., Ward, R. W., Ritchie, J. T., Fischer, R. A., and Schulthess, U. 1995. Vernalization in wheat I. A model based on the interchangeability of plant age and vernalization duration. Field Crops Res. 41:91-100.

Workneh, F., Jones, D. C., Heidel, G. B., Price, J. A., and Rush, C. M. 2008. Surveys of wheat viruses in the Texas Panhandle. (Abstr.) Phytopathology 98(suppl.):S173.

Workneh, F., Price, J. A., Jones, D. C., and Rush, C. M. 2010. Wheat streak mosaic: A classic case of plant disease impact on soil water content and crop water-use efficiency. Plant Dis. 94:771-774.

Xue, Q., Stewart, B. A., Lazar, M. D., Piccinni, G., and Salisbury, C. D. 2012. Genotypic variation in osmotic adjustment and transpiration efficiency among closely-related wheat lines. J. Crop Improv. 26:258-281.

Xue, Q., Rudd, J. C., Liu, S., Jessup, K. E., Devkota, R. N., and Mahan, J. R. 2014. Yield determination and water use efficiency of wheat under water-limited conditions in the US Southern High Plains. Crop Sci. 54: $34-47$. 